\title{
Makna Ritual Perayaan Mapag Sri bagi Warga Desa Segeran Kidul Kabupaten Indramayu
}

\author{
Ega Rifa Lifiani, Gregorius Genep Sukendro \\ egaliviani@gmail.com,geneps@fikom.untar.ac.id \\ Fakultas Ilmu Komunikasi Universitas Tarumangara
}

\begin{abstract}
Segeran Kidul is a village in Indaramayu area, West Java Province. Segeran Kidul Villagers are mostly working as a farmers. Segeran Kidul Village has traditional rituals related to farmers, it is called "Mapag Sri", Mapag means welcoming and Sri is the goddess of rice, Mapag Sri is a sacred activity for local community, this activity is carried out to welcome the arrival of the big harvest. The purpose of this research is to find out more about the meaning in the Mapag Sri ritual which is carried out once a year. The meaning contained in the Mapag Sri ritual is the gratitude of villagers of Segeran Kidul Village to God Almighty who gives bountiful harvests. The ritual is usually performed using an offering or "sesajen" as well as the Mapag Sri ritual which uses sesajen and tumpeng rice. The symbol attached to the Mapag Sri ritual is sharing activities for people in need and always be grateful to God by giving the bountiful harvest result. This research uses the symbolic interaction theory popularized by George Herbert Mead. This theory explains how the meaning that comes from the human mind about oneself at a social level which aims to interpret it in society.
\end{abstract}

Keywords: culture, mapag sri, segeran kidul, symbolic interaction, tradition.

\begin{abstract}
Abstrak
Desa Segeran Kidul merupakan desa yang berada di Indaramayu, Provinsi Jawa Barat. Desa ini memiliki mayoritas masyarakat yang bermatapencaharian sebagai petani. Desa Segeran Kidul memiliki ritual adat yang berkaitan dengan petani yaitu ritual Mapag Sri. Mapag berarti menyambut dan Sri adalah dewi padi. Mapag Sri adalah ucapara adat atau kegiatan sakral bagi masyarakat setempat, kegiatan ini dilaksanakan untuk menyambut datangnya panen raya. Tujuan dari penelitian ini adalah untuk mengetahui lebih jauh lagi makna yang ada di dalam ritual Mapag Sri yang dilakukan satu tahun sekali. Makna yang terdapat di dalam ritual Mapag Sri adalah rasa syukur masyarakat Desa Segeran Kidul kepada Tuhan Yang Maha Esa yang memberikan hasil panen yang melimpah. Ritual biasanya dilakukan dengan menggunakan sebuah sesajen sama halnya dengan ritual Mapag Sri yang menggunakan sesajen dan juga nasi tumpeng. simbol yang melekat pada ritual Mapag Sri yaitu melakukan kegiatan saling berbagi kepada orang yang membutuhkan dan selalu berterima kasih kepada Tuhan dengan memberikan hasil yang diingkan. Penelitian menggunakan teori interaksi simbolik yang dipopulerkan oleh George Herbert Mead. Teori ini menjelaskan bagaimana makna yang berasal dari pikiran manusia mengenai diri sendiri yang tengah berinteraksi sosial yang bertujuan untuk menginterpretasikan ditengah masyarakat.
\end{abstract}

Kata Kunci: budaya, interaksi dimbolik, mapag sri, segeran kidul, tradisi. 
Ega Rifa Lifiani, Gregorius Genep Sukendro: Makna Ritual Perayaan Mapag Sri bagi Warga Desa Segeran Kidul Kabupaten Indramayu

\section{Pendahuluan}

Indramayu merupakan sebuah kabupaten di Provinsi Jawa Barat Indonesia. Di Indonesia setiap daerahnya mempunyai sebuah budaya dengan berbagai ciri khas masing-masing dan berbeda-beda tempat asal mereka atau daerah tempat tinggal mereka yang terdapat di Indonesia, seperti halnya dengan daerah Indramayu yang memiliki kebudayaan tersendiri.

Desa Segeran Kidul yang berada di Kecamatan Juntinyuat Daerah Indramayu Provinsi Jawa Barat merupan desa yang mayoritas masyarakatnya adalah seorang petani. Desa ini dinamakan sebagai Desa Segeran karena bisa membawa suasana kebahagiaan, damai. Asal usul dari Desa Segeran Kidul yaitu pertama kali ada seseorang pemuda datang dari Cirebon lebih tepatnya dari Desa Tegal Gubug. Pemuda yang masih keturunan Kerajaan Majapahit itu mengembara ke Segeran dan melakukan babad alas di Segeran serta menetap hingga sekarang. Silsilah muncul karena adanya Ki Gede Segeran.

Di setiap daerah pasti memiliki sebuah ritual, sama hal dengan Desa Segeran Kidul yang memiliki ritual yang berkaitan dengan petani yaitu ritual Mapag Sri. Ritual ini salah satu di antara adat yang masih dilakukan di Desa Segeran Kidul. Sudah banyak ritual yang sudah ditinggal atau tidak dilaksanakan lagi di Desa Segeran Kidul. Mapag Sri itu adalah upacara adat atau kegiatan sakral bagi masyarakat Indramayu khususnya bagi masyarakat Desa Segeran Kidul. Kegiatan ini dilaksanakan untuk menyambut datangnya panen raya sebagai rasa syukur masyarakatnya kepada Tuhan Yang Maha Esa, yang telah memberikan mereka hasil yang melimpah dan sesuai dengan keinginan mereka. Kegiatan ini dilakukan hanya satu kali dalam satu tahun. Bagi masyarakat Indramayu ritual ini terhubung dengan mitos Dewi Sri atau Nyi Pohaci Sanghyang Sri yang diangggap sebagai dewi padi, dewi yang memberi sebuah kehidupan dan sebagai penuntun untuk orang-orang agar selalu berbagi tata cara menghormati serta mengerti arti dari kehidupan.

Penelitian ini ingin mengetahui bagaimana makna dari gunungan yang berisikan hasil bumi dari sebuah tradisi Mapag Sri bagi warga Desa Segeran Kidul, Kecamatan Juntinyuat, Indramayu. Tujuan dari penelitian ini adalah: 1) untuk mengetahui makna dari perayaan Mapag Sri bagi masyarakat desa segeran kidul; dan 2) untuk mengetahui lebih jauh lagi mengenai makna perayaan Mapag Sri bagi masyarakat Desa Segeran Kidul, serta melihat perkembangan makna dari tahun ke tahun.

Kegiatan ritual Mapag Sri yang dilakukan satu tahun sekali yang dimana kegiatan itu dilakukan untuk mengucap syukur kepada Tuha Yang Maha Esa. Kegiatan semua masyarakat setempat saling bahu membahu dan memberikan sebagian rizki mereka kepada orang yang membutuhkan, mereka akan melakukan makan bersama atau membagikan hasil dari bumi kepada sesame yang membutuhkan.

Ritual Mapag Sri memiliki makna bahwa ritual Mapag Sri adalah cara mereka mengucap syukur kepada sang pencipta yang telah ,memberikan hasil yang sesuai dengan apa yang diinginkan oleh petani. Kegiatan ritual ini sudah ada sejak zaman sahulu hingga sekarang ritual tersebut masih dilakukan. Teori interkasi simbolik mewakili dari bagaimana individu melihat sebuah simbol yang memiliki makna dan bagaimana individu menyesuaikan diri serta mengamati perilaku yang ada didalam interaksi sosial atau dilingkungan masyarakat. 


\section{Metode Penelitian}

Penelitian ini menggunakan pendekatan kualitatif. Krik dan Miller (1986) mendefinisikan bahwa penelitian kuantitatif adalah trdisi tertentu dalm ilmu pengetahuan sosial yang secara fundamental bergantung dari pengamat pada manusi baik dalam kawasanya (Anggito, 2018). Metode penelitian yang digunakan oleh penulis yaitu metode etnografi. Menurut Kuswarno, etnografi merupakan gabungan atau kesatuan pengetahuan yang meliputi teknik penelitian. Etnografi sendiri menjelaskan mengenai kebudayaan manusia dari sudut pandang orang lain yang mempelajari kebudayaan yang sama (Natalia dan Pribadi, 2020).

Dalam penelitian ini, penulis menentukan subyek dari penelitian yaitu pandangan masyarakat sekitar mengenai ritual Mapag Sri dan juga simbol yang ada didalamnya. Sedangkan obyek yang digunakan yaitu makna dari ritual Mapag Sri yang berada di Desa Segeran Kidul, Juntinyuat Indramayu.

Penelitian ini menggunakan beberapa teknik pengumpulan data, seperti observasi. Menurut Riyanto (2010), observasi merupakan metode pengumpulan data yang menggunakan pengamatan terhadap obyek penelitian yang dapat dilaksanan secara langsung maupun tidak langsung (Tanzeh,2011). Observasi yang dilakukan dengan pengamatan melalui media atau gambar mengenai ritual Mapag Sri yang ada di Desa Segeran Kidul Kecamatan Juntinyuat Kabupaten Indramayu. Kemudian yang kedua yaitu teknik wawancara, yakni kegiatan tanya jawab antara pewawancara (interviewer) dan masyarakat dari Desa Segeran Kidul sebagai terwawancara (interviewee). Wawancara yang digunakan oleh penulis yaitu semi-terstruktur (semistructure interview) atau in-depth interview, dengan menyediakan pertanyaan yang sesuai dengan konteks tetapi memberikan kesempatan kepada narasumber untuk memberikan pendapat mereka yang sesuai dengan konteks yang sedang dibahas. Serta penulis bisa saja memberikan pertanyaan secara spontan kepada narasumber.

Narasumber yang pertama yaitu bapak Safri, bekerja sebagai petani di Desa Segeran Kidul bahkan bapak Safri juga ikut bergabung kedalam kelompok tani, yakni kelompok yang mengelola dan memantau pertanian yang ada di Desa Segeran Kidul. Narasumber yang kedua yaitu bapak Jaman, bekerja sebagai wiraswasta dan juga sebagai tokoh masyarakat di Desa Segeran Kidul. Tringulasi dilakukan dengan narasumber berikutnya yaitu bapak Ahmad Yani, bekerja sebagai wiraswasta dan sekarang menjadi Kepala Desa di Desa Segeran Kidul.

\section{Hasil Temuan dan Diskusi}

Desa Segeran Kidul adalah salah satu desa yang terletak diwilayah Kecamatan Juntinyuat Kabupaten Indramayu Provinsi Jawa Barat. Desa Segeran merupakan desa dataran rendah yang biasanya diperuntukkan untuk perkampungan. Maka dari itu Desa Segeran Kidul adalah salah satu desa yang mayoritas masyarakatnya yaitu seorang petani, di mana setiap harinya masyarakat bercocok tanam seperti padi, mangga, sayur-sayuran. Petani memanfaatkan tanah masingmasing untuk mendapatkan penghasilan untuk keluarganya.

Bapak Safri mengatakan bahwa banyak hal yang sudah berubah dari tahun ke tahun, seperti halnya dengan kegiatan ritual Mapag Sri yang memiliki perubahan. Ritual Mapag Sri pada saat sekarang sudah tidak sama dengan ritual yang dilakukan pada saat zaman dahulu. Pada zaman dahulu kegiatan ritual Mapag Sri masih kental 
Ega Rifa Lifiani, Gregorius Genep Sukendro: Makna Ritual Perayaan Mapag Sri bagi Warga Desa Segeran Kidul Kabupaten Indramayu

dan asri sesuai dengan apa yang dilakukan oleh nenek moyangnya, tetapi pada saat sekarang kegiatan ritual Mapag Sri terdapat perubahan.

Sama halnya dengan bapak Safri, bapak Jaman juga berpendapat bahwa ritual Mapag Sri merupakan salah satu bagaimana masyarakat setempat untuk mengucap syukur kepada sang maha pencipta. Kegiatan ritual Mapag Sri itu seakan-akan diwajibkan sehingga semua masyarakat setempat melakukan kegiatan ini untuk kelanggengan dan kemasyarakatan pada masyarakat Desa Segeran Kidul. Kegiatan ini dilakukan dalam satu tahun sekali.

Menurut bapak Safri dan bapak Jaman, makna dari ritual Mapag Sri yaitu cara masyarakat Desa Segeran Kidul mengucap rasa syukur masyarakat setempat kepada Tuhan karena memberikan hasil panen yang melimpah. Kegiatan ritual Mapag Sri biasanya dilakukan dengan berbagi kepada sesama yang membutuhkan. Kegiatan ritual Mapag Sri masih dilakukan karena masyarakat setempat menghormati adat atau kebudayaan dari nenek moyang mereka, walaupun sudah ada yang berubah dari zaman dahulu dengan sekarang.

Dalam teori interaksi simbolik menurut George Herbert Mead, konsep dari interaksi simbolik ada poin yaitu berpikir (mind) artinya individu harus memahami simbol yang ada di dalam ritual Mapag Sri yang memiliki makna, yang kedua diri (self) artinya individu harus menyesuiakan dengan adanya sebuah ritual Mapag Sri di Desa Segeran Kidul dan yang terakhir yaitu masyarakat (society) artinya individu yang berada di Desa Segeran Kidul akan terlibat didalam ritual Mapag Sri yang dilakukan dalam satu tahun sekali.

Ketika individu melakukan poin tersebut maka individu akan mengetahui apa yang terjadi di dalam ritual Mapag Sri dengan melihat makna bagi masyarakat Desa Segeran Kidul. Tanpa disadari setiap individu akan melihat simbol yang ada didalam ritual Mapag Sri dan makna yang terdapat didalamnya.

Pada saat ini simbol yang ada di dalam ritual Mapag Sri sudah berkurang karena masyarakat setempat sudah jarang menggunakannya seperti adanya sebuah patung, gunungan yang berisikan hasil bumi, masyarakat lebih menderung melakukan tahil dan doa bersama kemudian memberikan hasil kepada orang yang memburuhkan. Berbeda dengan dahulu yang masih kental dengan adatnya.

Melihat proses yang telah dilakukan selama ini, maka perlu adanya evaluasi dengan memperbaiki proses yang sudah ada." (Sukendro dan Rusdi, 2018). Berdasarkan hal itu mengingat ritual Mapag Sri merupakan tradisi yang sudah lama dan menjadi identitas Desa Segeran Kidul Kecamatan Juntinyuat Kabupaten Indramayu. Untuk tetap melestarikan tradisi dalam keadaan pandemik dimana ada serangkaian protokol kesehatan yang harus diindahkan maka adanya evaluasi tentang tradisi atau perayaan ritual Mapag Sri yang dilaksanakan oleh Kepala Desa atau Kepada Adat untuk pembaharuan dan rekonstruksi tradisi diperlukan demi kelestarian tradisi Mapag Sri dikeadaan pandemik.

\section{Simpulan}

Kegiatan ritual Mapag Sri bertujuan untuk mengucapkan terima kasih dan rasa syukur terhadap Tuhan Yang Maha Esa yang selalu memberikan hasil panen yang melimpah, sehingga masyarakat dapat berbagi dengan sesama yang membutuhkan. Masyarakat Desa Segeran Kidul sangant antusias menyambut datangnya ritual Mapag Sri. Masyarakat saling gotong royong dan memberikan donasi untuk kelangsungan pelaksanaan ritual Mapag Sri, bukan hanya berupa donasi 
saja tetapi masyarakat juga bersama-sama membuat sebuah tumpeng nasi kuning yang nantinya dikumpulkan menjadi satu setelah itu dimakan bersama-sama.

Pada saat ini gunungan hasil bumi yang berupa padi, buah-buahan ataupun sayuran sudah jarang digunakan, kalaupun ada biasanya hanya gunungan padi yang kemudian diiringi dan memberikan rezeki kepada orang yang membutuhkan. Hal ini berbeda dengan zaman dahulu di mana harus ada gunungan hasil bumi. Perkembangan zaman membuat kegiatan dan juga cara-cara ritual sudah banyak yang tidak digunakan, salah satunya gunungan hasil bumi. Pada saat sekarang masyarakat cukup berdoa bersama kemudian makan-makan bersama serta berbagi kepada sesama yang membutuhkan.

Mengingat Indonesia kaya akan budaya, unsur kebudayaan yang ditonjolkan dalam iklan, dapat memberi gambaran, meningkatkan keingintahuan dan kebanggaan akan budaya Indonesia, serta memberikan wawasan edukatif yang lebih luas kepada masyarakat tentang ragam budaya Indonesia yang belum diketahui orang banyak, seperti perayaan Mapag Sri.

\section{Ucapan Terima Kasih}

Penulis mengucapkan terima kasih kepada pihak yang telah membantu penulis untuk mendapatkan informasi dan membantu penulis untuk menyelesaikan penelitian ini yaitu bapak Safri, bapak Jaman dan bapak Ahmad Yani atas kerjasamanya dengan penulis selama proses penelitian.

\section{Daftar Pustaka}

Albi Anggito, Johan Setiawan. (2018). Metodologi Penelitian Kualitatif. Sukabumi : Deepublish

Farid Rusdi, Gregorius Genep Sukendro, (2018). Analisis Industri Kreatif dalam Memanfaatkan Identitas Kota Melalui Media Baru. Jurnal Komunikasi Fakultas Ilmu komunikasi Universitas Trumanagara Vol. 10 No. 1 Hal. 1-8.

Fokus Pantura, (2019). Tingkatkan Hasil Produksi Pertanian, Pemdes Segeran Kidul Bangun TPT.

Lisuma, (2016). Tradisi Menyambut Padi (Mapag Sri) di Indramayu. Depok : Universitas Gunadarma.

Meydhita Stevanny, Muhammad Adi Pribadi (2020). Interaksi Simbolik dan Ekologi Media dalam Proses Keterlibatan Sebagai Roleplayer. Jurnal Komunikasi Fakultas Ilmu Komunikasi Universitas Tarumangara. Vol 4 No. 1 hal. 1-7.

Wartono. (2011). Segeran Kidul. Indramayu 